\title{
Acupuncture: Bridging the Gap Between the Military and Veterans' Health Systems
}

\author{
Cathaleen Madsen, $\mathrm{PhD}$, and Tracey Koehlmoos, $\mathrm{PhD}^{2}$
}

\begin{abstract}
This research brief describes the use of acupuncture as a mechanism for the development of crossagency knowledge translation and evidence-based practices in order to ensure the best possible care for the nation's veterans.
\end{abstract}

Keywords: military acupuncture, integrative medicine, pain management, veterans health, military health system, knowledge translation

\section{INTRODUCTION}

B EFORE TRANSITIONING to the Veterans Health Administration (VHA), members of the Armed Forces are beneficiaries of the Military Health System (MHS). Although both systems care for military personnel, the systems focus on different periods of service (active duty versus veteran) and are administered separately. The VHA is part of the Department of Veterans Affairs, is tasked with providing care to $\sim 21$ million veterans, and comprises the nation's largest integrated health system, with 170 medical centers, 1061 outpatient clinics, 300 veterans' centers, and 135 living centers. ${ }^{1,2}$ As many employed veterans choose private insurance through their employers, ${ }^{1}$ the VHA serves $\sim 9$ million veterans per year. ${ }^{2}$ In contrast, the MHS is part of the Department of Defense (DoD); is overseen by the Defense Health Agency; and provides care to $~ 9.5$ million active-duty military members, their dependents, and retirees under its universal-access TRICARE program. ${ }^{3}$ Beneficiaries may receive direct care from military treatment facilities (MTFs), including 55 hospitals and 373 military medical clinics, or from purchased care in the civilian sector. ${ }^{4}$
An estimated 270,000 service men and women transition each year from the MHS to the VHA. ${ }^{5,6}$ They can begin the process through Transition Assistance Program resources available at their local military installations. Service members with disabilities are assisted by the Integrated Disability Evaluation System (IDES), which facilitates informationsharing between the MHS and the VHA. Elimination of gaps in support is important for addressing issues that are common among current and former service members, particularly pain management.

The two systems share several important characteristics, including provision of integrative medicine for their beneficiaries. The integrative medicine model uses therapies both inside and outside of conventional medicine to achieve optimum whole-person health. This model is especially useful for treating chronic pain that presents alone or as part of the polytrauma triad with post-traumatic stress disorder (PTSD) and traumatic brain injury (TBI). In both health systems, acupuncture is used as a way to relieve pain without opioids for patients with a variety of conditions, although there are differences in access and delivery models.

\footnotetext{
${ }^{1}$ The Henry M. Jackson Foundation for the Advancement of Military Medicine, Inc., Bethesda, MD.

${ }^{2}$ Uniformed Services University of the Health Sciences, Bethesda, MD.

The contents of this publication are the sole responsibility of the authors and do not necessarily reflect the views, assertions, opinions, or policies of the Uniformed Services University of the Health Sciences, the Henry M. Jackson Foundation for the Advancement of Military Medicine, Inc., or the Departments of the Army, Navy, or Air Force. Mention of trade names, commercial products, or organizations does not imply endorsement by the U.S. government.
} 
Acupuncture was specifically recommended by the 2010 Pain Management Task Force, which sought to standardize care between the VHA and the DoD. ${ }^{7}$ While still considered alternative by some sources, ${ }^{8}$ acupuncture has been shown to be more effective than placebo for addressing headache, back pain, and neck pain, ${ }^{9}$ and has shown mixed but overall positive results for treating PTSD. ${ }^{10}$ Providers within the VHA report veterans actively requesting more acupuncture services, and acupuncture is one of the top two integrative medicine procedures to be referred to an outside provider. ${ }^{11}$ In contrast, within the MHS, acupuncture is provided only in the direct-care sector at MTFs and is not referred to the civilian purchased-care sector. In 2014, 11,000 active duty members received acupuncture within the MHS, with the majority of treatments being consistent with pain management. ${ }^{12}$

Multiple techniques are in use in the VHA as in the MHS, including scalp acupuncture, deep needling, and the auricular technique known as Battlefield Acupuncture (BFA). ${ }^{13}$ Courses in BFA were previously provided to both MHS and VHA participants through a program called Acupuncture Training across Clinical Settings (ATACS), a "train-thetrainers" initiative that sent acupuncture trainers to DoD and VHA sites over a 3-year period. ${ }^{14}$ This program, which ended in 2016, trained more than 2700 participants in BFA; the participants represented multiple provider types, exemplifying the capability for building a standardized capacity between the two agencies. ${ }^{14}$ Current opportunities for training in BFA in both the MHS and VHA vary by region and are internally supported by their respective systems.

Despite the wide range of provider types who may deliver this therapy, most acupuncture in both systems is performed by physician-acupucturists. ${ }^{12,15}$ Within the VHA, this is due in part to federal guidelines that were not formulated to show recognition of licensed acupuncturists (LAcs) as comprising an official professional category. Thus, these providers were necessarily hired as contractors rather than as direct employees of the VHA. ${ }^{15}$ This was partially addressed by a November 2017 decision by the Bureau of Labor Statistics that formally recognized acupuncturists with their own occupational codes, ${ }^{16}$ and was followed by the February 2018 qualification standard that officially allowed the VHA to hire LAcs. ${ }^{17}$ This is expected to smooth the way for greater inclusion of these providers within both health systems. Within the MHS, nonphysician providers who most commonly deliver acupuncture include chiropractors and physical therapists; physician extenders such as nurse-practitioners, physician assistants, and corpsmen; and mental or social health professionals. ${ }^{12}$

Within the larger context, acupuncture is part of the growing integrative medicine portfolio in both the VHA and the MHS. In the VHA, the Office of Patient Centered Care and Cultural Transformation has formed an Integrative Health Coordinating Center to support systemwide expansion and standardization of integrative medicine practices. This expansion focuses on those interventions with the strongest evidence bases-including acupuncture, chiropractic, t'ai chi, yoga, and meditation-and is part of the whole-health initiative, which seeks whole-person health for veterans instead of concentrating on specific symptoms. ${ }^{15}$ While a similar whole-person focus exists within the MHS, there is no equivalent center to serve as a single point of ownership for integrative medicine. Instead, multiple centers promote the use of integrative medicine within specific areas, notably the Defense and Veterans Brain Injury Center (DVBIC), the Psychological Health Center of Excellence, the Defense and Veterans Center for Integrative Pain Management (DVCIPM), and the National Intrepid Center of Excellence. A total of 23 integrative therapies across 15 modalities are reported in use across the MHS, ranging from clinical standards such as cognitive-behavioral therapy, to body-based techniques such as chiropractic and yoga, to various mindfulness and meditative exercises. ${ }^{18}$ Similarly, like the situation in the VHA, these therapies are not standardized across treatment facilities, and efforts to increase access are frequently patient-driven. ${ }^{18,19}$

Taken together, this comparison of the VHA and the MHS shows multiple opportunities for acupuncture to serve as a point of crossagency capacity building, knowledge sharing, and care standardization. While the DoD has provided leadership for several bridging efforts, including the DVCIPM, DVBIC, the ATACS program, and the Pain Management Task Force, the VHA holds significant resources in the Integrative Health Coordinating Center. This group could potentially serve as the point of contact to synchronize efforts across the two systems, and to model the formation of a similar agency within the DoD. At the patient level, the IDES process can prepare patients for any differences in access to acupuncture between the MHS and the VHA. In the future, as medical records become standardized between the two systems, requests for access could be forwarded administratively in order to track, fulfill, and predict future demand for this therapy within the VHA.

For the estimated 270,000 military service men and women who transition each year to the VHA, ${ }^{5,6}$ acupuncture and other integrative therapies are familiar treatment options for conditions such as chronic pain. Previous research demonstrates that these men and women will actively seek and request these therapies. The VHA is well-positioned to capitalize on using these therapies, both to serve as a transition point from the MHS and to reduce the risk of opioid dependence among our nation's veterans. Common training settings enhance the bridge further between the MHS and the VHA, together presenting a platform for knowledge-sharing between the two systems and ensuring evidence-based practices for our current and former military members.

\section{AUTHOR DISCLOSURE STATEMENT}

No competing financial interests exist. 


\section{REFERENCES}

1. Hutchinson J, Mack R, Koehlmoos T, DeLeon PH. Lessons for Health Equity: Military Medicine as a Window to Universal Health Insurance. Discussion Paper. Washington, DC: National Academy of Medicine, 2015. Online document at: https:// nam.edu/wp-content/uploads/2016/11/Lessons-for-Health-EquityMilitary-Medicine-as-a-Window-to-Universal-Health-Insurance. pdf Accessed June 26, 2018.

2. United States Department of Veterans Affairs. Veterans Health Administration. About VHA. Online document at: www.va.gov/ health/aboutvha.asp Accessed June 26, 2018.

3. TRICARE. About Us-Number of Beneficiaries. Online document at: www.tricare.mil/About/Facts/BeneNumbers Accessed February 24, 2017.

4. TRICARE. About Us-Health and Dental Facilities. Online document at: www.tricare.mil/About/Facts/Facilities Accessed February 24, 2017.

5. Military One Source Office of the Deputy Assistant Secretary of Defense. 2015 Demographics: Profile of the Military Community. 2015. Online document at: download.militaryonesource.mil/ 12038/MOS/Reports/2015-Demographics-Report.pdf Accessed April 5, 2018.

6. Zogas, A. Watson; Institute International and Public Affairs. US Military Veterans' Difficult Transitions back to Civilian Life and the VA's Response. Providence, RI: Brown University; 2017.

7. Office of the Army Surgeon General. Pain Management Task Force Report: Providing a Standardized DoD and VHA Vision and Approach to Pain Management to Optimize the Care for Warriors and their Families. 2010. Online document at: www.dvcipm.org/site/assets/files/1070/pain-task-force-finalreport-may-2010.pdf Accessed February 3, 2017.

8. Wieland LS, Manheimer E, Berman BM. Development and classification of an operational definition of complementary and alternative medicine for the Cochrane Collaboration. Altern Ther Health Med. 2011;17(2):50-59.

9. Hopton A, MacPherson H. Acupuncture for chronic pain: Is acupuncture more than an effective placebo? A systematic review of pooled data from meta-analyses. Pain Pract. 2010; 10(2):94-102.

10. Wahbeh H, Senders A, Neuendorf R, Cayton J. Complementary and alternative medicine for post-traumatic stress disorder symptoms: A systematic review. J Evid Based Complementary Altern Med. 2014;19(3);161-175.
11. Gaudet T, Vandenberg P. FY 2015 VHA Complementary \& Integrative Health Services (Formerly CAM). Healthcare Analysis \& Information Group (HAIG). May 2015. Online document at: sciencebasedmedicine.org/wp-content/uploads/ 2016/07/FY2015_VHA_CIH_signedReport.pdf Accessed April 8, 2018.

12. Madsen C, Patel A, Vaughan M, Koehlmoos T. Use of acupuncture in the United States military health system. Med Acupunct. 2018;30(1):33-38.

13. Helms JM. Medical acupuncture meets the military. Med Acupunct. 2017; 29(4):189-190.

14. Niemtzow R, Baxter J, Gallagher RM, et al. Building capacity for complementary and integrative medicine through a large, cross-agency, acupuncture training program: Lessons learned from a military health system and Veterans Health Administration joint initiative project. Mil Med. 2018; March 26:epub ahead of print.

15. Kligler B. Integrative health in the Veterans Health Administration. Med Acupunct. 2017;29(4):187-188.

16. National Certification Commission for Acupuncture and Oriental Medicine. New Independent SOC for Acupuncturists Proposed by the BLS for 2018. Online document at: www.nccaom.org/ resource-center/bls-timeline/ Accessed April 5, 2018.

17. United States Department of Veterans Affairs. VA Handbook 5005/100 Transmittal Sheet: Staffing. February 7, 2018. Online document at: www.va.gov/vapubs/viewPublication.asp?Pub_ID= 909\&FType=2 Accessed July 18, 2018.

18. Madsen C, Vaughan M, Koehlmoos T. Use of integrative medicine in the United States military health system. Evid Based Complementary Altern Med. 2017;2017:9529257.

19. Denneson LM, Corson K, Dobscha S. Complementary and alternative medicine use among veterans with chronic noncancer pain. JRRD 2011;48(9):1119-1128.

Address correspondence to: Cathaleen Madsen, PhD

The Henry M. Jackson Foundation for the Advancement of Military Medicine, Inc. 6720A Rockledge Drive Bethesda, MD 20817

E-mail: cathaleen.madsen.ctr@usuhs.edu 